\title{
Physicochemical and Toxicity Investigation of Chitosan- based dsRNA Nanocarrier Formation
}

\author{
Maicon S. Petrônio 1(D), Tais T. Barros-Alexandrino ${ }^{2}$ (D), Aline M. F. Lima ${ }^{1}$ (D), Odilio B. G. Assis ${ }^{2}$ (D), \\ Alice K. I. Nagata $^{3(D)}$, Erich Y. T. Nakasu ${ }^{3(D)}$, Marcio J. Tiera ${ }^{1(D)}$, Lucimeire Pilon ${ }^{4 *}{ }^{(D)}$ \\ 1 Institute of Biosciences, Letters and Exact Sciences; São Paulo State University (UNESP); 15054-000 São José do Rio \\ Preto, SP; Brazil \\ 2 National Nanotechnology Laboratory for Agriculture (LNNA); Embrapa Instrumentation; 13560-970 São Carlos, SP, \\ Brazil \\ 3 Laboratory of Virology and Molecular Biology; Embrapa Vegetables; BR-060, Km 09, 70275-970 Brasília, DF; Brazil \\ 4 Laboratory of Food Science; Embrapa Vegetables; BR-060, Km 09, 70275-970 Brasília, DF; Brazil \\ * Correspondence: lucimeire.pilon@embrapa.br (L.P.);
}

Scopus Author ID 13606819100

Received: 6.07.2021; Revised: 20.08.2021; Accepted: 25.08.2021; Published: 18.10.2021

\begin{abstract}
Technologies involving the use of double-stranded RNA (dsRNA) to elicit RNA interference (RNAi) in pest control have emerged as an alternative to traditional pesticides. RNAi can mediate natural cell protection being a promising tool to provide prompt responses in plant defense against pathogens. The present study is focused on the physicochemical characterization of formed dsRNAloaded nanoparticles as a result of chitosan-dsRNA ionic interactions. Additionally, a preliminary investigation was conducted of the in-vitro toxicity of loaded nanoparticles in lettuce and human red blood cells. dsRNA molecules, homologous to partial phytopathogenic tomato mosaic virus (ToMV) sequence, were used as a model. The main groups involved in the chitosan-dsRNA ionic coupling were identified by Fourier-transform infrared spectroscopy, and the stability of formed nanoparticles was accessed by dynamic light scattering, electrophoresis, and thermal analyses. The chitosan showed a higher ability to bind to dsRNA at low charge ratios $(\mathrm{N} / \mathrm{P}=1)$, ruled by positively charged chitosan methyl groups and negatively charged phosphate groups from the RNA backbone, resulting in small nanoparticles ( $73.25 \mathrm{~nm}$ size) at low polydispersity (0.25). The toxic assays of these particles, on lettuce seeds and in human erythrocytes, revealed very low toxicity demonstrating their safety as a platform, thereby holding potential use as biodefensive for crop protection.
\end{abstract}

Keywords: chitosan nanocarrier; tomato mosaic virus (ToMV); dsRNA phytotoxicity assay.

(C) 2021 by the authors. This article is an open-access article distributed under the terms and conditions of the Creative Commons Attribution (CC BY) license (https://creativecommons.org/licenses/by/4.0/).

\section{Introduction}

Advanced techniques in biotechnology have been proposed as tools to mitigate crop diseases, mainly controlling pests through genetic improvement of plants, and more recently, by developing nanoparticles carrying genes to prevent or cure infectious diseases [1-6].

Researches focused on reducing exposure, and consequently, pest resistance to pesticides is an urgent and challenging matter [7,8]. In this context, molecular gene silencing rises as cutting-edge technology for acting as a mediator on plants' resistance mechanisms, especially for viruses $[9,10]$, as no curative products are available.

RNA interference (RNAi) is a natural protection mechanism of cells and a promising tool to elicit plant defense responses against pathogens [11-13]. This mechanism is triggered by the presence of long double-stranded RNA (dsRNA) in the cytoplasm, which is processed 
by Dicer-like enzymes (DCLs) into 20 to 25 nucleotide-molecules termed short interfering RNAs (siRNAs). The siRNAs are incorporated into an RNA-induced silencing complex (RISCs) that recognizes and degrades complementary RNAs. The recognition process is based on the complementarity between nucleotide sequences, so the target is highly specific [14].

In plants, exogenously applied dsRNA molecules can traffic intracellular and systemically [15], prompting RNAi responses via topical application, as demonstrated against viruses of the genera Tobamovirus, Potyvirus, and others Alfamovirus [16-19]. However, topically naked dsRNA for preventing or treating plant diseases is limited by two main barriers. The first refers to environmental factors that can degrade the dsRNA before reaching the target cells. In the environment, the degradation can be initiated either by thermal action or exposure to the UV-light range [20, 21]. The other refers to physical barriers, such as the waxy cuticle of leaves and cell walls [22].

Inorganic or organic nanocarriers systems attempts to overcome these issues are feasible for protecting and delivering dsRNA molecules. Clay nanosheets, as layered coatings [23], and organic-based nanoparticles such as polysaccharides, liposomes, and cationic dendrimers [24] have been successfully tested for pest management.

Chitosan, for instance, is a versatile biopolymer that can undergo chemical modifications relatively easily, making it one of the most popular nanocarrier delivery platforms under investigation. The chitosan molecular structure is well known, consisting of random copolymers of $(\beta 1 \rightarrow 4)$ 2-amino-2-deoxy-D-glucopyranose $(\mathrm{GlcN})$ and $(\beta 1 \rightarrow 4) 2$ acetamido-2-deoxy-D-glucopyranose (GlcNAc) units [25]. In a mild acid medium, the amino groups of chitosan are protonated to $-\mathrm{NH}_{3}+$ conferring a cationic character to the polymer. These positively charged groups are prone to interact electrostatically, in solution, to the negatively charged phosphate groups present in the nucleic acid structure, collapsing into stable nanostructures [26]. Hence, these complexes are potential non-viral vectors for efficient gene delivery [27].

Thus, the present study is focused on the chitosan-dsRNA interactions and the physicochemical properties of the dsRNA-loaded nanoparticles, including cytotoxicity and hemolysis assays. dsRNA molecules homologous to a partial genome of the phytopathogenic tomato mosaic virus (ToMV) were used as the model virus. The combination of chitosan's antimicrobial properties and its delivery capability provides a potential for ds-RNAnanoparticles to deliver dsRNA as a tool for virus disease control in crops.

\section{Materials and Methods}

\subsection{Synthesis of chitosan/dsRNA nanoparticles.}

Chitosan (MW 190,000-310,000 g/mol, 75\% degree of deacetylation units) was purchased from Sigma-Aldrich Chemical Co. (St. Louis, MO, USA). All solvents were reagent grade and used as received. The dsRNA homologous to the coat protein region of the ToMV genome of 456 bp (MW 281.726 kDa, 41.9\% GC, GenBank accession LC556234, nt 10-4652) was purchased from AgroRNA (Songpa-gu, Seoul, Korea).

Nanoparticles were prepared by coacervation process at varied polymer-dsRNA charge ratio $(\mathrm{N} / \mathrm{P})$, calculated as the molar ratio of the chitosan amino charges $(\mathrm{N})$ to the phosphate (P) groups of dsRNA. The polymer was previously solubilized in $0.1 \mathrm{~mol} \mathrm{~L}^{-1} \mathrm{HCl}$ solutions and subsequently diluted in double distilled water to obtain a stock solution at $2.0-2.5 \mathrm{mg} \mathrm{mL}^{-}$

1 . Finally, chitosan solutions were added to dsRNA solutions $\left(200 \mu \mathrm{g} \mathrm{mL} \mathrm{mL}^{-1}\right)$ under gentle 
magnetic stirring for $3 \mathrm{~min}$ at room temperature [28]. Different proportions of chitosan/dsRNA (0.5:1, 1:1, 3:1 and 5:1) were prepared.

\subsection{Fourier-transform infrared spectroscopy (FTIR).}

Chitosan-dsRNA interactions were investigated by attenuated total reflection (ATR) measurements using a Vertex 70 Fourier-transform infrared FTIR spectrometer (Bruker, Germany). ATR IR spectra on neat chitosan and chitosan/dsRNA complex were recorded in absorbance mode in an ATR accessory equipped with a single reflection diamond crystal. Each spectrum was collected at a resolution of $4 \mathrm{~cm}^{-1}$ with 64 scans over the range of $4000-400 \mathrm{~cm}^{-}$ 1. Identification of peak position and spectra analysis were conducted using the Origin 8.0 software (Origin Lab, Northampton, MA, USA).

\subsection{Particle size distribution, polydispersity index, and zeta potential.}

The particle size distribution and zeta potentials were determined by dynamic light scattering using a Zeta Potential Analyzer (Zetasizer ZS 3600, Malvern Instruments, UK). The nanoparticle solutions (NPs) were prepared and measured in triplicate at $25{ }^{\circ} \mathrm{C}$. The results were expressed as the mean value from three independent experiments. Data were analyzed using a one-way analysis of variance (ANOVA) in a Tukey test at $\mathrm{p}>0.05$, by using Statistical Analysis System v. 8.0 [29]. Data were expressed as the means ( $\pm \mathrm{SD})$ of six replicates.

\subsection{Morphology.}

The nanoparticles morphology was observed under a field-emission gun scanning electron microscope JSM-6701F (FEG-SEM, JEOL, MA, USA). Nanoparticles from the chitosan/dsRNA N/P ratio of 1:1 was chosen as the best ratio, as determined in preliminary assays. For microscopic observation, the nanoparticle solution was diluted with ultrapure water (Milli-Q) to the final proportion of 1:20 by ultrasonication in a bath for $15 \mathrm{~min}$. The sonicated nanoparticles solution was deposited on a silicon wafer, spontaneously dried, and coated with carbon. All samples were examined at an accelerating voltage of $10.0 \mathrm{kV}$. To compare the particle size observable in SEM to the Zetasizer determination, the length of 100 isolated particles was directly measured on the micrographs using the ImageTool 3.0 program (UT Health Science Center, San Antonio, TX, USA).

\subsection{Thermal properties (TGA and DSC).}

The thermal stability of nanoparticles was characterized on a TGA Q500 (TA Instruments, New Castle, DE, USA). Freeze-dried samples of $10 \mathrm{mg}$ were heated at a constant rate of $10^{\circ} \mathrm{C} \mathrm{min}{ }^{-1}$ over a temperature range of 30 to $800{ }^{\circ} \mathrm{C}$ and a nitrogen flow rate of $60 \mathrm{~mL}$ $\mathrm{min}^{-1}$. To estimate and compare the amount of mass loss associated with each degradation step, the onset and end-set temperatures (where the thermal degradation begins and ends, respectively) were considered and identified on TGA inflection points.

DSC (differential scanning calorimetry) analysis was performed using a Differential Scanning Calorimeter Q100 (TA Instruments, New Castle, DE, USA). Samples of $5 \mathrm{mg}$ were hermetically sealed in an aluminum pan and heated at a constant rate of $10^{\circ} \mathrm{C} \mathrm{min}{ }^{-1}$ over a temperature range of 25 to $360{ }^{\circ} \mathrm{C}$. The inert atmosphere was maintained by purging nitrogen

gas at a flow rate of $50 \mathrm{~mL} \mathrm{~min}^{-1}$. The essayed nanoparticles were those prepared considering 
the N/P ratio 1:1 (CH/dsRNA). Peaks identifications and area determination (enthalpy for the transitions) were performed using Origin 8.0 (Origin Lab, Northampton, MA, USA).

\subsection{Gel retardation assay.}

Complimentary assessment of interaction strength between chitosan and dsRNA in the formed nanoparticles was evaluated by electrophoresis in agarose gel $0.8 \%$, in tris-acetate acidEDTA buffer (TAE-1X), and stained with ethidium bromide (10 mg mL-1). The $1 \mathrm{~kb}$ Plus DNA ladder (Thermo Fisher Scientific, Waltham, MA, USA) was used as a marker The complexes formed in different N/P $\left({ }^{+} I_{-}\right)$ratios, with a fixed amount of dsRNA $200 \mu \mathrm{g}$ was incubated in ultrapure water for $30 \mathrm{~min}$ at room temperature. Then, $10 \mu \mathrm{L}$ of the complex was loaded in each well of the agarose gel, using bromophenol blue to fix the nanoparticle solution. After the electrophoresis $(80 \mathrm{~V}, 90 \mathrm{~min})$, the gel was exposed to UV light $(254 \mathrm{~nm})$, and the picture was taken with a photo documentation system.

\subsection{Phytotoxicity assay on lettuce (Lactuca sativa) seeds.}

Prior to the toxicity assay, a pre-test on seed germination was carried out to confirm its viability [30]. Lettuce seeds cv. Leila were placed in Gerbox ${ }^{\circledR}$ on two layers of humidified filter paper with an amount of distilled water corresponding to 2.5 times the weight of the dry paper. Each box containing 50 seeds was incubated at $20^{\circ} \mathrm{C}$ and an $8 \mathrm{~h}$ photoperiod, totaling 200 seeds in four replications.

The phytotoxicity assay was performed using $28 \mathrm{~cm}^{2}$ Petri dishes with 10 seeds arranged in an equidistant manner per dish and three replicates per treatment. The treatments were carried out as follows: 1) CH 1:1 dsRNA TOMV; 2) dsRNA TOMV $200 \mu \mathrm{g} \mathrm{mL}^{-1}$; 3) chitosan solubilized in $0.1 \mathrm{~mol} \mathrm{~L}^{-1}$ of $\mathrm{HCl}$; 4) $0.1 \mathrm{~mol} \mathrm{~L}^{-1}$ of $\mathrm{HCl}$ solution (vehicle control) and 5) distilled water (negative control). The dishes were incubated in a BOD (LimaTec, LT320 TFP-II, Brazil) at $20^{\circ} \mathrm{C}$ and an $8 \mathrm{~h}$ photoperiod. The counting started on day 4 and continued up to day 7. Germinated seeds were considered to have approximately $15 \mathrm{~mm}$ of radicle protrusion. The bioassay was performed in 7 days. Primary root length and shoot length were evaluated using a ruler.

\subsection{Hemolysis assay.}

The hemolytic activities of nanoparticle and dsRNA suspensions on human red blood cells (RBCs) were evaluated [31]. The blood was freshly collected by venipuncture using the Vacutainer $^{\circledR}$ vacuum system in sterile and disposable tubes containing ethylenediaminetetraacetic acid tripotassium phosphate salt (EDTA-K3) as an anticoagulant. The experimental tubes contained the nanoparticle suspensions at different ratios (chitosan/dsRNA (0.5:1, 1:1, 3:1 and 5:1) plus RBCs diluted in PBS at a 1:4 (v/v) ratio. As positive and negative controls, $1 \%$ Triton X-100 solution and Phosphate-buffered saline $(\mathrm{pH}$ 7.4), were used, respectively. Samples were incubated at $37^{\circ} \mathrm{C}$ for $90 \mathrm{~min}$ and then centrifuged at $1500 \mathrm{rpm}$ for $10 \mathrm{~min}$. The supernatant was quantified by spectrophotometry at $560 \mathrm{~nm}$ using an Elx 808 Microplate Reader (BioTek, USA). The hemolysis rate was calculated using the relation: hemolysis $\%=[$ (sample absorbance - negative control absorbance $) /($ positive control absorbance - negative control absorbance) $] \times 100$. 


\subsection{Ethics committee.}

The blood collection was carried out at the Hemoglobin and Hematologic Genetic Diseases Laboratory UNESP/IBILCE (State University of São Paulo, SJRP, SP, Brazil). All experiments were approved by the Ethics Committee under number 68620317.5.0000.5466.

\section{Results and Discussion}

\subsection{Characterization by Fourier-transform infrared spectroscopy (FTIR).}

The FTIR characterization of the dsRNA chitosan complex was evaluated by analyzing chitosan spectral changes as indicative of the participation of charged groups in the complexation. Free RNA absorbance bands were also considered, similar to Namdar et al. (2013) [32] and Joozdani et al. (2015) [33]. The interpretation of RNA complex spectra is rather challenging since the amino and hydroxyl groups overlap a series of peaks in the same spectral region. However, some indications of the electrostatic interaction between moieties can be deferred.

A broad peak around $3200 \mathrm{~cm}^{-1}$ was observed (Figure 1 (a)), typically showing the symmetric stretching vibration of $\mathrm{OH}$ groups in positions $\mathrm{C} 3$ and $\mathrm{C} 6$ in the chitosan structure. The region between 1500 to $1180 \mathrm{~cm}^{-1}$, enlarged in (Figure 1 (b1)), corresponds to amide III absorbances, mainly bending vibration modes of the $\mathrm{CH}_{2}$ in $\mathrm{CH}_{2} \mathrm{OH}$ and $\mathrm{CH}_{3}$ in $\mathrm{NHCOCH}_{3}$ groups [34]. In this region, two discrete signals emerged in the complex spectra, the chitosandsRNA complex showing higher absorbance values (Figure 1 (b1)). The first one $\left(1346 \mathrm{~cm}^{-1}\right.$ ) likely results from the RNA groups, hydrogen or ionically-bonded, to the $\mathrm{C}-\mathrm{H}$ in the methyl groups of amide [35]. The second $\left(1300 \mathrm{~cm}^{-1}\right)$ is a typical asymmetric stretching band of phosphate groups $\left(\mathrm{PO}_{2-}^{-}\right)$from the RNA backbone [35, 36].

Another region of significant absorbance variation was observed at $\sim 1050 \mathrm{~cm}^{-1}$, enlarged in Figure 1 (b2). It is related to the symmetric and asymmetric C-O-C stretching in the $\beta$-1,4-glycosidic linkage present in chitosan [37], which decays abruptly by $900 \mathrm{~cm}^{-1}$. According to Ouameur et al. (2010) [38], this is a strong indication of the electrostatic interaction between the $\mathrm{NH}_{3}{ }^{+}$group of chitosan and phosphoric counter ions, which are the predominant groups $\left(\mathrm{PO}_{2}^{-}\right)$in the RNA strand.

The region marked as 3 corresponds to phosphate-sugar vibrations. Some peaks, not present or overlapped in the neat chitosan spectrum, are better defined in the RNA expanded region (Figure 1 (b3)). Two peaks are worthy of signaling in the complex, at 766 and $735 \mathrm{~cm}^{-}$ ${ }^{1}$ relative to deoxyribose, free or coupled, vibrations [39].

\subsection{Particle size distribution, polydispersity index (PDI), and zeta potential.}

Charge adjustment is an important parameter for polyplex formation between cationic polymers and genetic material (anionic) [40]. Depending on the molecular weight, a mix of small and larger nanoparticles can be formed by recruiting the smaller structures into aggregates [41, 42]. According to the DLS measurements, nanoparticles with an N/P 0.5 ratio resulted in the largest particles with an average size of $1235 \mathrm{~nm}$ (Figure 2 (a)). The poor charge interactions due to the proportional higher amount of dsRNA in solution lead to an easy aggregation of RNA into large and irregular clusters, as confirmed by the polydispersity index (PDI) of 0.65 (Figure 2 (b)). The predominance of anionic species in the complex due to the excess of RNA is confirmed by the negative zeta potential values (Figure 2 (a)). 
When the proportion of chitosan is increased to N/P 1.0 ratio, an efficient complexation between the two species is confirmed by the formation of small nanostructures, with a mean value of $73.25 \mathrm{~nm}$ (Figure 2 (a)) and zeta potentials of $-9,0 \mathrm{mV}$, ensuring good particle stability, in agreement with a significant reduction of the measured PI (0.25) (Figure 2 (b)).
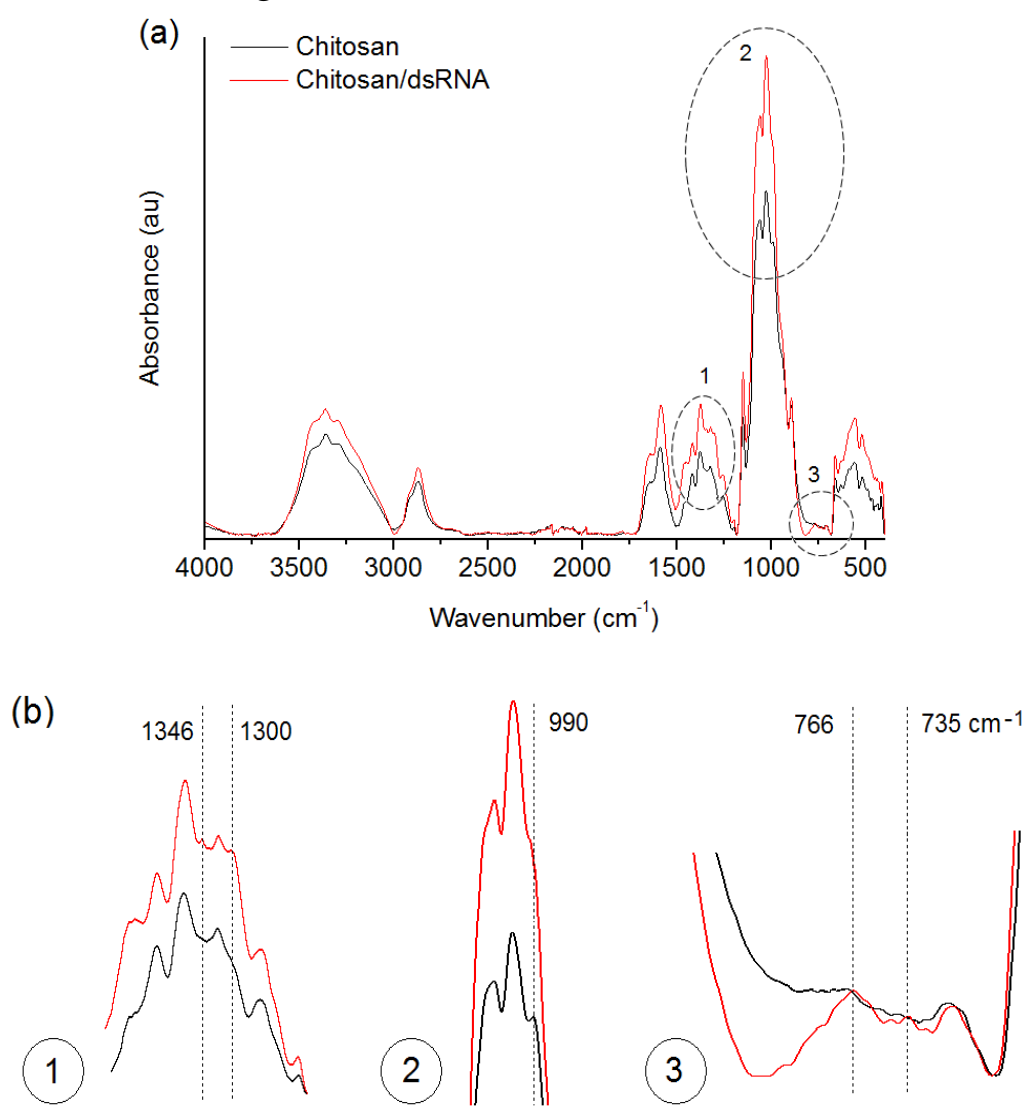

Figure 1. (a) FTIR spectra of chitosan and chitosan/dsRNA complex. (b) Details of vibrations in the regions assigned in the frame.

As the N/P ratio was increased to 3 and 5, it resulted in the formation of small-sized nanoparticles, with mean diameters of $156.28 \mathrm{~nm}$ and $153.62 \mathrm{~nm}$, respectively (Figure 2 (a)), with no significant statistical difference in the polydispersity index (PDI) between these complexes (Figure 2 (b)). In contrast, the zeta potential increased to +6.86 and $+7.98 \mathrm{mV}$ for the 3 and $5 \mathrm{~N} / \mathrm{P}$ ratios, respectively. It was expected since the greater the amount of chitosan, the higher the density of positive amino groups on the particles' surfaces.
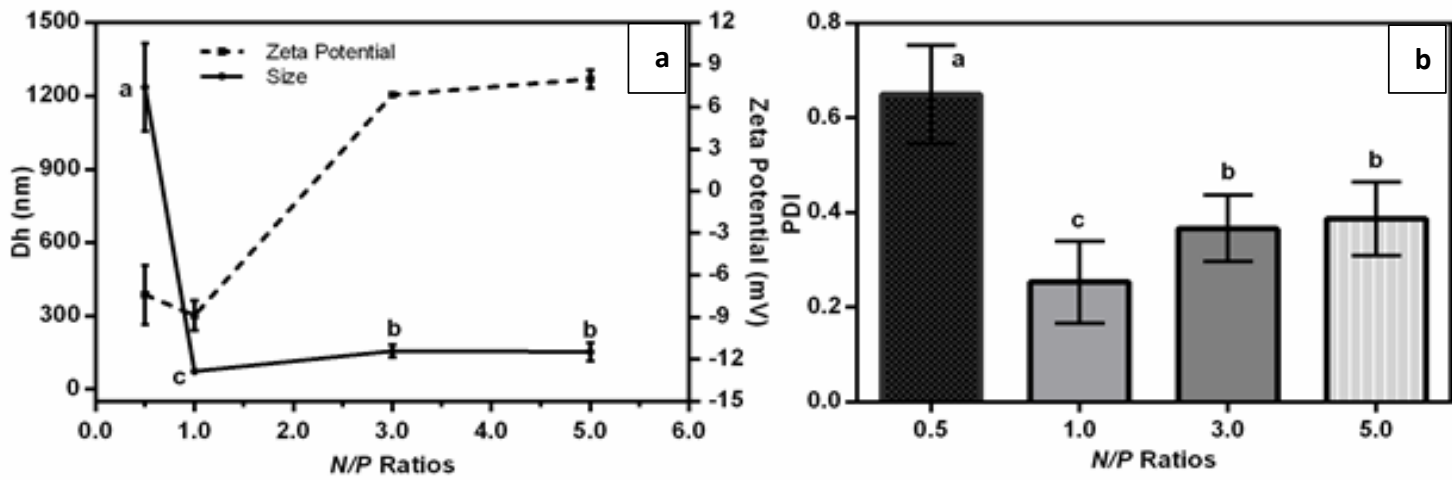

Figure 2. (a) Hydrodynamic diameters (Dh) and zeta potential of CH-dsRNA, and (b) polydispersity index (PDI). Means with different letters differ from each other by the LDS test $(\mathrm{P}<0.05)$. 
3.3. Field emission gun scanning electron microscopy (FEG-SEM).

Nearly spherical nanoparticles of $62.96 \pm 17.32 \mathrm{~nm}$ on average were observed in the chitosan with dsRNA N/P = 1 ratio preparation in a FEG-SEM (Figure 3). Two-fused particles were also observed at a low rate. The particle sizes measured by FEG-SEM were slightly smaller than those obtained by DSL $(73.25 \mathrm{~nm})$, indicating that the actual sizes are spread out over a large range of values, not differing statistically from the DLS results.

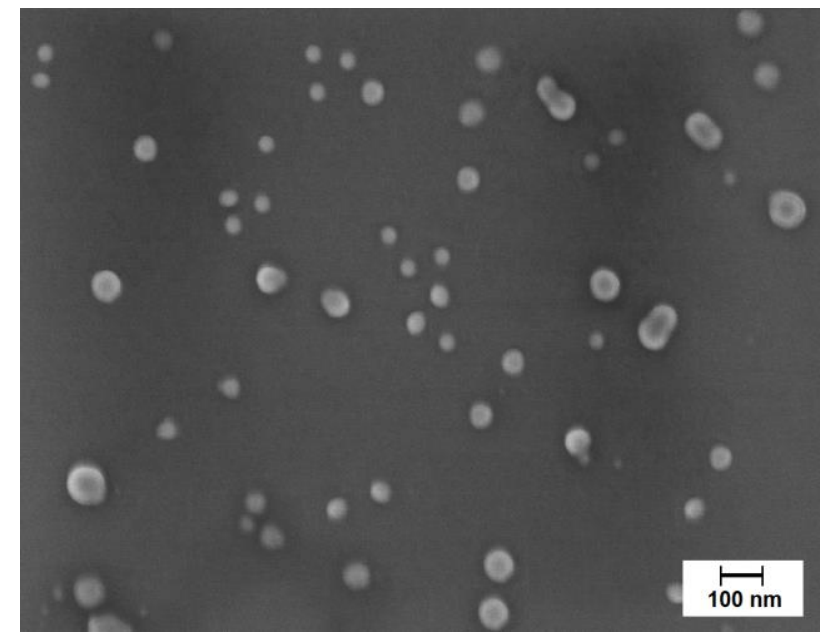

Figure 3. FEG-SEM of nanoparticles as obtained from chitosan/dsRNA complexation at N/P ratio 1.0.

\subsection{Thermal analysis (TGA) and (DSC).}

TGA allows the monitoring of the weight losses as a function of temperature, indirectly reflecting the structural stability of the analyzed samples. The degradation curves reveal some differences concerning the thermal behavior between samples, as observed by the TG profiles (Figure 4(a)). Three main events were identified in both samples, starting with the evaporation of volatile constituents held by weak interactions, mainly water, with maximum detachment up to $128^{\circ} \mathrm{C}$ for chitosan and lower temperature for the complex dsRNA-chitosan $\left(70{ }^{\circ} \mathrm{C}\right)$. The weight losses for both samples were similar, consisting of about $13 \%$. The amount of retained water depends on the available polar groups in the structure, mainly hydroxyl and amine. Despite the electrostatic interactions between the amino and phosphate groups promoting a reduction in the polymer polarity, the equal amount of water evaporated indicates compensation by the presence of polar amino acids from the dsRNA in the complex.

The second degradation event could be identified at $290^{\circ} \mathrm{C}$ for chitosan, characterized by a sharp weight loss up to $336^{\circ} \mathrm{C}$. It is most likely related to oxidative backbone degradation, destroying the amine groups. In contrast, the complex showed a continuous weight loss from $70{ }^{\circ} \mathrm{C}$ on. This profile reflects the gradual elimination of the remaining volatile compounds and the degradation of low molecular weight RNA fractions. At $238{ }^{\circ} \mathrm{C}$, it is supposed that the bonds established between chitosan and dsRNA are broken. In this temperature range, the absence of an abrupt thermal event in the complex can be considered a result of strong ionic interaction established between amino groups from chitosan and phosphate groups from dsRNA [43] as also suggested by the FTIR analyzes.

The third stage was identified at $\sim 263{ }^{\circ} \mathrm{C}$ when it is expected that the dsRNA was already completely degraded [44]. Both samples had similar behavior from this point on, attributed to the irreversible degradation of the chitosan structure's acetylated and deacetylated 
glucosamine units [45]. From $522{ }^{\circ} \mathrm{C}$, production of $\mathrm{CO}_{2}$ is expected, followed by total depolymerization and decarbonylation until complete pyrolitic decomposition.
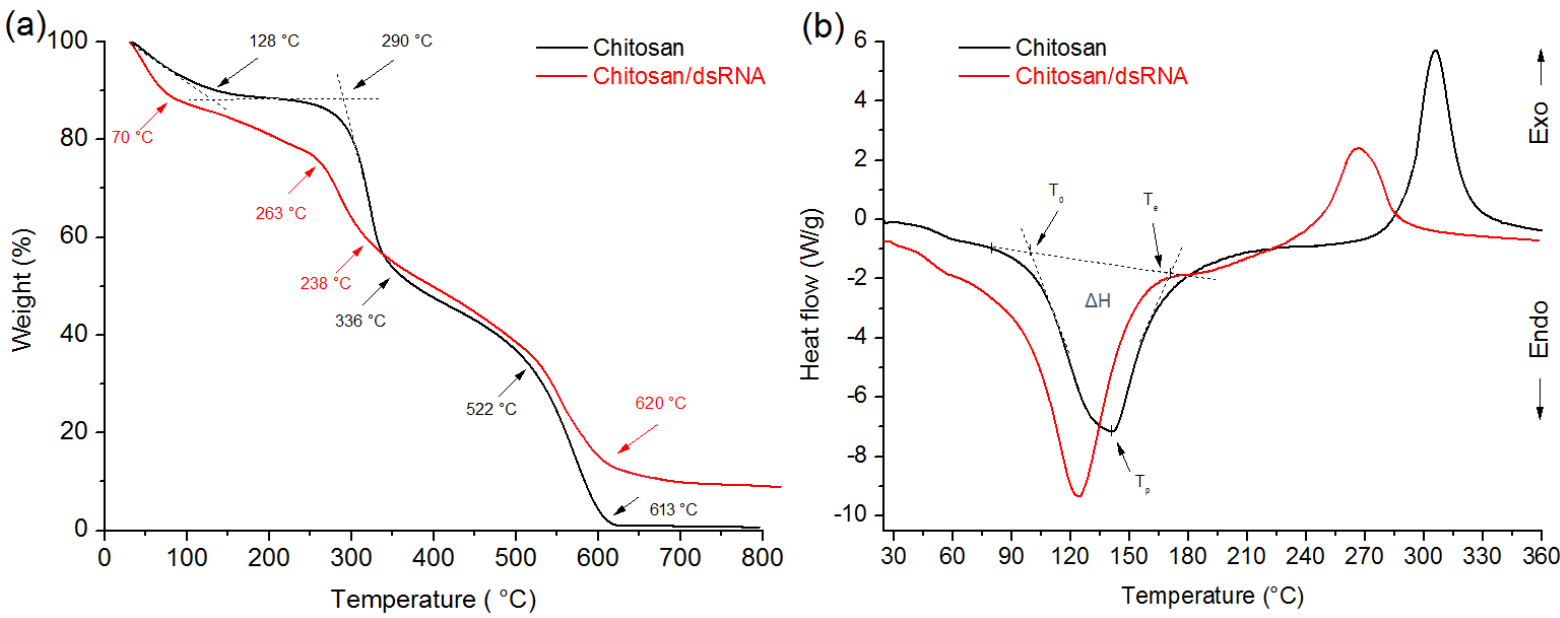

Figure 4. (a) TGA thermograms of neat chitosan and chitosan/dsRNA complex, with main temperature events assigned. (b) Heat flow vs. temperature in DSC analysis of chitosan and chitosan/dsRNA.

At the end of the thermal cycle, at $613{ }^{\circ} \mathrm{C}$, the chitosan sample was completely charred, with no remaining residual mass. A solid residue of approximately $10 \%$ of the initial mass was observed in the complex sample at $\sim 700{ }^{\circ} \mathrm{C}$. The superior residual mass measured to the complex may be related to the crystalline and morphological variations in the complex concerning those of the neat chitosan [46]. The temperature interval and corresponding loss of mass are summarized in Table 1.

Table 1. Temperature intervals and correspondent mass losses according to TG analyses.

\begin{tabular}{c|c} 
Temperature interval $\left({ }^{\circ} \mathbf{C}\right)$ & Weight loss (\%) \\
\hline \multicolumn{2}{|c|}{ Chitosan } \\
\hline $25-128$ & 13 \\
\hline $330-336-522$ & 35 \\
\hline $522-620$ & 17 \\
\hline $25-70$ & Chitosan/dsRNA Complex \\
\hline $70-263$ & 13 \\
\hline $263-238$ & 14 \\
\hline $238-620$ & 40
\end{tabular}

Complementary thermal analysis was carried out by DSC (Figure 4(b) and Table 2). The DSC thermograms exhibited two distinct degradation stages, with one endothermic and one exothermic peak in both samples. The endothermic peak centered at $140{ }^{\circ} \mathrm{C}$ observed for the neat chitosan sample was typical and related to water dissociation [24, 47]. On the other hand, the endothermic peak was shifted to $125^{\circ} \mathrm{C}$ when the complex was analyzed, indicating that the interaction of water with this complex is likely weaker than with the raw chitosan.

The calculated enthalpy $(\Delta \mathrm{H})$ in these areas (the energy necessary to break down the water hydrogen bonds) indicates the strength in which the water molecules are interconnected with the sorption sites. By calculating the associated endothermic enthalpies, it was found that the complex demands approximately 13\% more energy per unit mass for the complete water evaporation (Table 2). However, it was faster (end-set at $152{ }^{\circ} \mathrm{C}$ ) than with chitosan (end-set at $171{ }^{\circ} \mathrm{C}$ ). A possible explanation is that the complex has fewer amino groups available to form hydrogen bonds with water molecules. Therefore, in the complex structure, most water molecules will be bound preferentially to chitosan and RNA hydroxyl groups. As the hydrogen 
bonds with the hydroxyl groups are stronger than those with the amino groups [48], a greater enthalpy of dissociation is expected. This interpretation agrees with the previous one obtained by TG analysis and corroborates the vibration modes assigned in FTIR analysis.

The exothermic peaks, centered at $307^{\circ} \mathrm{C}$ for neat chitosan and $264^{\circ} \mathrm{C}$ for the complex, are related to the rupture and structural degradation. In chitosan, the process starts at $286{ }^{\circ} \mathrm{C}$ and is related to the decomposition of amine $(\mathrm{GlcN})$ unities in the polymer backbone. The lower decomposition temperature found for the complex reflects a decrease in thermal stability. Additionally, the lower exothermic enthalpy indicates that the interactions reduced the polymer crystallinity, resulting in greater amorphous regions in the complex structure [49], associated with lower RNA molar heat capacity [50]. It is known that the higher the crystallinity, chain mobility is reduced, and consequently, more heat is necessary for its decomposition [51].

Table 2. DSC thermal transitions of chitosan and chitosan/dsRNA. $\mathrm{T}_{\mathrm{o}}$ : onset temperature; $\mathrm{T}_{\mathrm{p}}$ : peak temperature;

$\mathrm{T}_{\mathrm{e}}$ : completion temperature (endset), and $\Delta \mathrm{H}$ : enthalpy.

\begin{tabular}{l|c|c|c|c} 
& $\mathbf{T}_{\mathbf{0}}\left({ }^{\circ} \mathbf{C}\right)$ & $\mathbf{T}_{\mathbf{p}}\left({ }^{\circ} \mathbf{C}\right)$ & $\mathbf{T}_{\mathbf{e}}\left({ }^{\circ} \mathbf{C}\right)$ & $\Delta \mathbf{H}(\mathbf{J} / \mathbf{g})$ \\
\hline Chitosan & \multicolumn{5}{|c}{ Endothermic } \\
\hline Chitosan/dsRNA & 100 & 140 & 171 & 371 \\
\hline Chitosan & 98 & 125 & 152 & 426 \\
\hline Chitosan/dsRNA & 286 & 307 & 324 & -107 \\
\hline
\end{tabular}

\subsection{Electrophoresis.}

Figure 5 presents the gel electrophoresis indicating that the chitosan/dsRNA ratio of $0.5: 1$ was the only which resulted in partial complexation (lane 2). All the other tested ratios $(1: 1,3: 1$, and 5:1), evidenced the complete formation of dsRNA-loaded nanoparticles (lanes 3 , 4 , and 5 respectively). When DNA is in contact with chitosan, the complexation is driven by the electrostatic interaction mainly between amine groups in chitosan and phosphate groups in DNA, as previously presented and discussed through infrared and thermal analyses. The gel retardation is a complementary assay that indicates that the electrophoretic mobility was retard with an increasing amount of chitosan. In other words, the complex formation becomes efficient for proportions above 0.5:1 chitosan/dsRNA.

\subsection{Phytotoxicity assay.}

The germination was confirmed in $98.5 \%$ of the seeds, showing the viability for conducting the phytotoxicity tests. The allelopathic effects of tested mediums on seeds are summarized in Table 3. The results reveal that the complexations of chitosan/dsRNA N/P, at the ratio of $1: 1$, induced the greatest shoot development with statistical significance (at $\mathrm{P}>0.05$ ) from the other treatments. Several studies have reported chitosan as a plant growth promoter, which has been attributed to its hydrophilic nature, acting positively in reducing stress damage and accelerating several biological activities, such as a better synthesis of cytokines, hormones stimulating cell division, and/or auxins, hormones stimulating cell elongation [52-54]. Concerning the radicle lengths, no significant effect was observed at any treatment (Table 3) during the evaluation time, suggesting no interference or any inhibitory effect on roots development. 


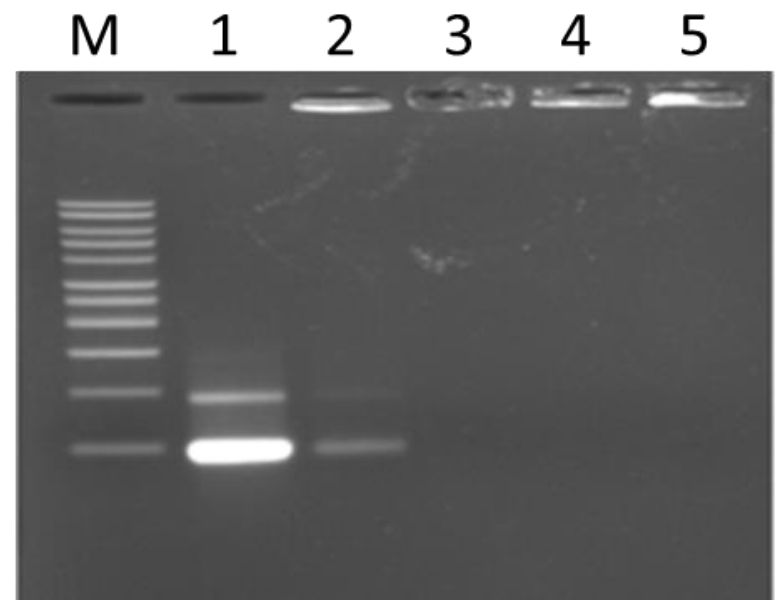

Figure 5. Gel electrophoresis of nanoparticles prepared with chitosan at increasing chitosan:dsRNA charge ratios (N/P). M: 1 kb Plus ladder; ToMV CP dsRNA only (lane 1) followed by N/P of 0.5 (lane 2), 1 (lane 3), 3 (lane 4) and 5 (lane 5). The dsRNA bound to polyplexes does not migrate under electrophoresis and is seen fluorescing in the well.

Table 3. Radicle and shoot lengths of lettuce 'Leila' seedlings germinated in chitosan-dsRNA, dsRNA, chitosan, $\mathrm{HCl}$, and distilled water.

\begin{tabular}{l|c|c}
\multicolumn{1}{c|}{ Treatments } & Shoot length $(\mathbf{c m})$ & Radicle length $(\mathbf{c m})$ \\
\hline Chitosan-dsRNA & $1.41^{\mathrm{a}}$ & $3.99^{\mathrm{a}}$ \\
\hline dsRNA & $1.26^{\mathrm{b}}$ & $3.75^{\mathrm{a}}$ \\
\hline Chitosan & $1.20^{\mathrm{bc}}$ & $3.84^{\mathrm{a}}$ \\
\hline HCl & $1.14^{\mathrm{bc}}$ & $3.61^{\mathrm{a}}$ \\
\hline Water & $1.08^{\mathrm{c}}$ & $3.92^{\mathrm{a}}$
\end{tabular}

Means followed by the different letters in the column differ by the Tukey test $(\mathrm{p}<0.05)$.

Coefficient of variation (CV). Shoot length: $C V=16.8 \%$; Radicle length: $C V=21.9 \%$.

\subsection{Hemolysis assay.}

An efficient delivery system must be premised on being safe, non-cytotoxic, nonimmunogenic, and mainly non-hemolytic. In this sense, the in vitro hemolysis test is an essential tool in providing information about the ability of the nanocarriers to disrupt the red blood cells. According to the International Organization of Standardization [55], the hemolysis index of a biomaterial cannot be higher than $5 \%$.

In the present study, the chitosan/dsRNA nanoparticles showed low blood toxicity for all N/P ratios, being all inferior to 5\% compared to the positive control (Triton X-100), as displayed in Table 4. In terms of toxicity outcomes, the low hemolytic activity of chitosan nanoparticles has been previously confirmed [56]. However, physicochemical parameters of the used chitosan, such as the molecular mass and deacetylation degree, can disturb the erythrocyte membrane and lead to hemolysis or even aggregation [57]; additionally, the electrostatic interaction between positive charges of chitosan and negative sites on the erythrocyte membrane, could create surface net leading to hemagglutination [58].

Table 4. Hemolytic percentage induced by chitosan/dsRNA nanoparticles.

\begin{tabular}{c|c} 
N/P ratios & Hemolysis $(\%)$ \\
\hline Triton (positive control) & 100 \\
\hline 0.5 & 1.08 \\
\hline 1.0 & 0.87 \\
\hline 3.0 & 1.08 \\
\hline 5 & 1.62 \\
\hline PBS (negative control) & 0
\end{tabular}


In view of all these findings, the low hemolysis rate recorded on the complexed nanoparticles corresponds to the neutrality range according to NCL Method PCC-2. This is a fundamental parameter to ensure the safety of the application of these nanocarriers.

\section{Conclusions}

The results show that small-sized chitosan nanoparticles loaded with dsRNA can be successfully prepared by the coacervation method. Spectroscopic and thermal analyses confirmed that complexation is driven by strong ionic interactions between species, preferably involving the positively charged chitosan methyl groups and negatively charged phosphate groups from the RNA backbone. Stable particles are attained by complete binding, which occurs to chitosan/dsRNA ratio above 1:1, according to gel electrophoresis analysis. Toxicity assays on lettuce seeds and the human erythrocytes resulted in low toxicity. Based on these findings, the nanoparticles prepared by the chitosan-dsRNA system proved to be safe, having a great potential to be exploited as nanocarriers for delivering active genes to control and prevent plant diseases.

\section{Funding}

This research was funded by Embrapa, grant number 13.16.04.007.00.00, and FAP-DF grant number 0193.001197/2016.

\section{Acknowledgments}

The authors acknowledge V. F. Soares for her assistance in the Electron Microscope operation and A. C. Thomazi for thermal analyzes, both from Embrapa Instrumentação, São Carlos, SP. We also thank M. P. S. Cabrera and C. R. B. Domingos for access to instrumentation; and C. M. Rêgo-Machado for assistance in dsRNA preparation.

\section{Conflicts of Interest}

The authors declare no conflict of interest.

\section{References}

1. Dong, O. X.; Ronald, P. C. Genetic Engineering for Disease Resistance in Plants: Recent Progress and Future Perspectives. Plant Physiology 2019, 180, 26-38, https://doi.org/10.1104/pp.18.01224.

2. Rego-Machado, C.M.; Nakasu, E.Y.T.; Silva, J.M.F.; Lucinda, N.; Nagata, T.; Inoue-Nagata, A. K. siRNA biogenesis and advances in topically applied dsRNA for controlling virus infections in tomato plants. Scientific Reports 2020, 10, 22277, https://doi.org/10.1038/s41598-020-79360-5.

3. Wytinck, N.; Manchur, C. L.; Li, V. H.; Whyard, S.; Belmonte, M. F. dsRNA uptake in plant pests and pathogens: Insights into RNAi-based insect and fungal control technology. Plants 2020, 9, 1780, https://doi.org/10.3390/plants9121780.

4. Gebremichael, D. E.; Haile, Z. M.; Negrini, F.; Sabbadini, S.; Capriotti, L.; Mezzetti, B.; Baraldi, E. RNA interference strategies for future management of plant pathogenic fungi: prospects and challenges. Plants 2021, 10, 650, https://doi.org/10.3390/plants10040650.

5. Giudice, G.; Moffa, L.; Varotto, S.; Cardone, M. F.; Bergamini, C.; De Lorenzis, G.; Velasco, R.; Nerva, L.; Chitarra, W. Novel and emerging biotechnological crop protection approaches. Plant Biotechnol J. 2021, 116, https://doi.org/10.1111/pbi.13605.

6. Yan, S.; Ren, B.; Zeng, B.; Jie Shen. Improving RNAi efficiency for pest control in crop species. BioTechniques 2020, 68, 283-290, https://doi.org/10.2144/btn-2019-0171. 
7. Isman, M. B. Challenges of pest management in the twenty-first century: New tools and strategies to combat old and new foes alike. Frontiers in Agronomy 2019, 1, 2, https://doi.org/10.3389/fagro.2019.00002.

8. Pugsley, C.E.; Isaac, R. E.; Warren, N. J.; Cayre, O. J. Recent Advances in Engineered Nanoparticles for RNAi-Mediated Crop Protection Against Insect Pests. Frontiers in Agronomy 2021, 3, 652981, 1-19, https://doi.org/10.3389/fagro.2021.652981.

9. Goldbach, R.; Bucher, E.; Prins, M. Resistance mechanisms to plant viruses: an overview. Virus Research 2003, 2, 207-212, https://doi.org/10.1016/s0168-1702(02)00353-2.

10. Ricci, A.; Sabbadini, S.; Miozzi, L.; Mezzetti, B.; Noris, E.. Host-induced Gene Silencing and Spray-induced Gene Silencing for Crop Protection Against Viruses. In: RNAi for Plant Improvement and Protection, 1st ed., Mezzetti, B., Sweet, J., Burgos, L. (eds), 72-85. CAB International, UK 2021, https://doi.org/10.1079/9781789248890.0000.

11. Abbas, U.; Khan, H. M.; Faisal, M.; Ayub, I.; Shafqat, K.; Tahir, T. Role of Interference RNA (RNAi) in plant disease management. Transactions in Physical and Biochemical Sciences 2021, 1, 69-84, https://doi.org/10.2144/btn-2020-0098.

12. Borah, M.; Konakalla, N. C. RNAi Technology: A novel platform in crop protection. In: Emerging Trends in Plant Pathology, 1st ed., Singh, K. P.; Jahagirdar, S.; Sarma, B. K. (eds), 561-575. Springer, Singapore 2021, https://doi.org/10.1007/978-981-15-6275-4.

13. Niu, D.; Hamby, R.; Sanchez, J. N.; Cai, Q.; Yan, Q.; Jin, H. RNAs - a new frontier in crop protection. Current Opinion in Biotechnology 2021, 70, 204-212, https://doi.org/10.1016/j.copbio.2021.06.005.

14. Price, D. R. G.; Gattehouse, J. A. RNAi-mediated crop protection against insects. Trends in Biotechnology 2008, 26, 393- 400, https://doi.org/1.10.1016/j.tibtech.2008.04.004.

15. Melnyk, C.W.; Molnar, A.; Baulcombe, D.C. Intercellular and systemic movement of RNA silencing signals. The EMBO Journal 2011, 30, 3553-3563, https://doi.org/10.1038/emboj.2011.274.

16. Tenllado, F.; Martinez-Garcia, B.; Vargas, M.; Diaz-Ruiz, J. Crude extracts of bacterially expressed dsRNA can be used to protect plants against virus infections. BMC Biotechnology 2003, 3, 3, https://doi.org/10.1186/1472-6750-3-3.

17. Tenllado, F.; Llave, C.; Diaz-Ruiz, J.R. RNA interference as a new biotechnological tool for the control of virus diseases in plants. Virus Research 2004, 102, 85-96, https://doi.org/10.1016/j.virusres.2004.01.019.

18. Yin, G.; Sun, Z.; Liu, N.; Zhang, L.S.; Song, Y.; Zhu, C.; Wen, F. Production of double-stranded RNA for interference with TMV infection utilizing a bacterial prokaryotic expression system. Applied Microbiology and Biotechnology 2009, 84, 323 -333, https://doi.org/0.1007/s00253-009-1967-y.

19. Schwartz, S.H.; Hendrix,B., Hoffer, P.; Sanders, R. A.; Zheng, W. Carbon dots for efficient small interfering RNA delivery and gene silencing in plants. Plant Physiology, 2020, 184, 647-657, https://doi.org/10.1104/pp.20.00733.

20. Bachman, P.; Fischer, J.; Song, Z.; Urbanczyk-Wochniak, E.; Watson, G. Environmental fate and dissipation of applied dsRNA in soil, aquatic Systems, and plants. Frontiers in Plant Science 2020, 11, https://doi.org/10.3389/fpls.2020.00021.

21. Christiaens, O.; Petek, M.; Smagghe, G.; Taning, C. N. T.. The use of nanocarriers to improve the efficiency of RNAi-based pesticides in agriculture. In: Nanopesticides, 1st ed.; Fraceto L.F., de Castro, V.L.S.S.; Grillo R.; Ávila D.; Oliveira H.C.; Lima R. (eds). Springer, Cham 2020. https://doi.org/10.1007/978-3-030-448738_3.

22. Bennett, M.; Deikman, J.; Hendrix, B.; Iandolino, A. Barriers to Efficient Foliar Uptake of dsRNA and Molecular Barriers to dsRNA Activity in Plant Cells. Frontiers in Plant Science 2020, 11, 816, https://doi.org/10.3389/fpls.2020.00816.

23. Mitter, N.; Worrall, E.A.; Robinson, K.E.; Li, P.; Jain, R. G.; Taochy, C.; Fletcher, S. J.; Carroll, B. J.; Lu, G. Q. M.; Xu, Z. P. Clay nanosheets for topical delivery of RNAi for sustained protection against plant viruses. Nature Plants 2017, 3, 16207, https://doi.org/10.1038/nplants.2016.207.

24. Yan, S.; Ren, B-Y.; Shen, J. Nanoparticle-mediated double-stranded RNA delivery system: A promising approach for sustainable pest management. Insect Science 2021, 28, 21-34, https://doi.org/10.1111/17447917.12822.

25. Goy, R. C.; Britto, D.; Assis, O. B. G. A review of the antimicrobial activity of chitosan. Polímeros 2009, 9 , 241-247, https://doi.org/10.1590/S0104-14282009000300013.

26. Agirre, M.; Zarate, J.; Ojeda, E.; Puras, G.; Desbrieres, J.; Pedraz, J. L. Low molecular weight chitosan (LMWC)-based polyplexes for pDNA delivery: from bench to bedside. Polymers 2014, 6, 1727-1755, https://doi.org/10.3390/polym6061727. 
27. Bravo-Anaya, L. M.; Soltero, J. F. A.; Rinaudo, M. DNA/chitosan electrostatic complex. International Journal of Biological Macromolecules 2016, 345-353, https://doi.org/10.1016/j.ijbiomac.2016.03.035.

28. Martins, G. O.; Petrônio, M. S.; Furuyama, A. M. L.; Martinez Jr, A. M.; Tiera, V. A. O.; Calmon, M. F.; Leite, P. S. V.; Han, S. W.; Tiera, M. J. Amphipathic chitosans improve the physicochemical properties of siRNA-chitosan nanoparticles at physiological conditions. Carbohydrate Polymers 2019, 216, 332-342, https://doi.org/10.1016/j.carbpol.2019.03.098.

29. SAS Institute (Cary, North Carolina). SAS OnlineDoc® 1999, Version 8. Availible in: http://www.math.wpi.edu/saspdf/common/mainpdf.htm.

30. BRASIL. Ministério da Agricultura, Pecuária e Abastecimento. Secretaria de Defesa Agropecuária. Regras para análise de sementes. Brasília, DF 2009, 395.

31. Li, Y.; Xu, B.; Bai, T.; Liu, W. Co-delivery of doxorubicin and tumor-suppressing p53 gene using a POSSbased star-shaped polymer for cancer therapy. Biomaterials 2015, 55, 12-23, https://doi.org/10.1016/j.biomaterials.2015.03.034.

32. Namdar, R.; Makouie, N.; Nafisi, S. Study on the interaction of homoisoflavonoids with RNA. Journal of Photochemistry and Photobiology B: Biology $2013, \quad 128, \quad 100-106$, https://doi.org/10.1016/j.jphotobiol.2013.08.019.

33. Joozdani, F.A.; Yari, F.; Joozdani, P.A.; Nafisi, S. Interaction of Sulforaphane with DNA and RNA. PLoS ONE 2015, 10, e0127541, https://doi.org/10.1371/journal.pone.0127541.

34. Pasels, B. R.; Castillo, A. P.; Simon, R.; Pulido, M. T.; Mana-Ay, H.; Abiquibil, M. R.; Montecillo, R.; Thumanu, K.; Von Tumacder, D.; Taaca. K. L. Synthesis and Characterization of Acetic Acid-Doped Polyaniline and Polyaniline ${ }^{-}$Chitosan Composite. Biomimetics 2019, 4, 15, https://doi.org/10.3390/biomimetics4010015.

35. Mello, M. L. S.; Vidal, B. C. Analysis of the DNA Fourier transform-infrared microspectroscopic signature using an all-reflecting objective. Micron 2014, 61, 49-52, https://doi.org/1.10.1016/j.micron.2014.02.003.

36. Neault, J. F.; Tajmir-Riach, H. A. Structural analysis of DNA-chlorophyll complexes by Fourier Transform Infrared Difference Spectroscopy. Biophysical Journal 1999, 76, 2177-2182, https://doi.org/10.1016/S00063495(99)77372-8.

37. Nair, V.; Panigrahy, A.; Vinua, R. Development of novel chitosan-lignin composites for adsorption of dyes and metal ions from wastewater. Chemical Engineering Journal 2014, 254, 491-502, https://doi.org/10.1016/j.cej.2014.05.045.

38. Ouameur, A. M.; Bourassa, P.; Tajmir-Riahi, H-A. Probing tRNA interaction with biogenic polyamines. $R N A$ 2010, 16, 1968-1979, https://doi.org/10.1261/rna.1994310.

39. Liquier, J.; Akhebat, A.; Taillandier, E.; Ceolin, F.; Huynh-Dinh, T.; Igolen. J. Characterization by FTIR spectroscopy of the oligoribonucleotide duplexes r(A-U)6 and r(A-U)8. Spectrochimica Acta Part A: Molecular Spectroscopy 1991, 47, 177-186, https://doi.org/10.1016/0584-8539(91)80089-2.

40. Malmo, J.; Varum, K. M.; Strand, S. P. Effect of chitosan chain architecture on gene delivery: comparison of self-branched and linear chitosans. Biomacromolecules 2011, 12, 721-729, https://doi.org/10.1021/bm1013525.

41. Howard K. A.; Raubek, U. L.; Liu, X.; Damgaard, C. K.; Glud, S. Z.; Aandersen, M. Ø.; Hovgaard, M. B.; Schimitz, A.; Nyengaard, J. R.; Besenbacher, F.; Kjems, J. RNA Interference in vitro and in vivo using a novel chitosan/siRNA nanoparticle system. Molecular Therapy 2006, 14, 476-484, https://doi.org/10.1016/j.ymthe.2006.04.010.

42. Lameiro, M. H.; Lopes, A.; Martins, L. O.; Alves, P. M.; Melo, E. Incorporation of a model protein into chitosan-bile salt microparticles. International Journal of Pharmaceutics 2006, 312, 119-130, https://doi.org/10.1016/j.ijpharm.2006.01.006.

43. Moussout, H.; Ahlafi, H.; Aazza, M.; Bourakhouadar, M. Kinetics and mechanism of the thermal degradation of biopolymers chitin and chitosan using thermogravimetric analysis. Polymer Degradation and Stability 2016, 130, 1-9, https://doi.org/10.1016/j.polymdegradstab.2016.05.016.

44. Saha, B.; Kumar, G. S. Spectroscopic and calorimetric investigations on the binding of phenazinium dyes safranine-O and phenosafranine to double stranded RNA polynucleotides. Journal of Photochemistry \& Photobiology B: Biology 2016, 161, 129-140, https://doi.org/10.1016/j.jphotobiol.2016.03.062.

45. Martins, C. S.; Morgado, D. L.; Assis, O. B. G. Cashew gum-chitosan blended films: Spectral, mechanical and surface wetting evaluations. Macromolecular Research 2016, 24, 691-697, https://doi.org/10.1007/s13233016-4103-8.

46. Ramya, B. R.; Sudha, P. N.; Mahalakshmi, J. Preparation and characterization of chitosan binary blend. International Journal of Scientific and Research Publications 2012, 2, 1-9, https://doi.org/10.1002/pip.1166. 
47. Mucha, M.; Pawlak, A. Thermal analysis of chitosan and its blends. Thermochimica Acta 2005, 427, 69-76, https://doi.org/10.1016/j.tca.2004.08.014.

48. Neto; C. G. T; Giacometti, J. A.; Job, A. E.; Ferreira, F. C.; Fonseca, J. L. C.; Pereira, M. R. Thermal analysis of chitosan based networks. Carbohydrate Polymers 2005, 62, 97-103, https://doi.org/10.1016/j.carbpol.2005.02.022.

49. Ma, G.; Yang, D.; Zhou, Y.; Xiao, M.; Kennedy, J. F. Niea, J. Preparation and characterization of watersoluble N-alkylated chitosan. Carbohydrate Polymers 2008, 74, 121-126, https://doi.org/10.1016/j.carbpol.2008.01.028.

50. Saha, B.; Kumar, G. S. Binding interaction of phenothiazinium dyes with double stranded RNAs: Spectroscopic and calorimetric investigation. Journal of Photochemistry and Photobiology B: Biology 2017, 167, 99-110, https://doi.org/10.1016/j.jphotobiol.2016.12.022.

51. Salmah, H.; Faisal, A.; Kamarudin, H. Chemical modification of chitosan-filled polypropylene (PP) composites: The effect of 3-Aminopropyltriethoxysilane on mechanical and thermal properties. International Journal of Polymeric Materials and Polymeric Biomaterials 2011, 60, $429 \quad-\quad 440$, https://doi.org/10.1080/00914037.2010.531812.

52. Agbodjato, N. A.; Noumavo, P. A.; Adjanohoun, A.; Agbessi, L.; Baba-Moussa, L. Synergistic effects of plant growth promoting rhizobacteria and chitosan on in vitro seeds germination, greenhouse growth, and nutrient uptake of maize (Zea mays L.). Biotechnology Research International 2016, 2016, ID 7830182, https://doi.org/10.1155/2016/7830182.

53. Divya, K.; Smitha, V.; Jisha, M. Antifungal, antioxidant and cytotoxic activities of chitosan nanoparticles and its use as an edible coating on vegetables. International Journal of Biological Macromoecules 2018, 114, 572577, https://doi.org/10.1016/j.ijbiomac.2018.03.130.

54. Muthukrishnan, S.; Murugan, I.; Selvaraj, M. Chitosan nanoparticles loaded with thiamine stimulate growth and enhances protection against wilt disease in Chickpea. Carbohydrate Polymers 2019, 212, 169-177, https://doi.org/10.1016/j.carbpol.2019.02.037.

55. ISO document 10 993-5 1992. Biological evaluation of medical devices, Part 4, Selection of tests for interactions with blood.

56. Rondon, E. P.; Benabdoun, H. A.; Vavlières, F.; Petrônio, M. S.; Tiera, M. J.; Benederdour, M.; Fernandes, J. C. Evidence supporting the safety of pegylated diethylaminoethyl-chitosan polymer as a nanovector for gene therapy applications. International Journal of Nanomedicine 2020, 15, 61836200, https://doi.org/10.2147/IJN.S252397.

57. Yang, J.; Tian, F.; Wang, Z.; Wang, Q.; Zeng, Y-J.; Chen, S-Q. Effect of chitosan molecular weight and deacetylation degree on hemostasis. Journal of Biomedical Materials Research - Part B 2008 84,131-137, https://doi.org/10.1002/jbm.b.30853.

58. Lima, J. M.; Sarmento, R. R.; de Souza, J. R.; Brayner, F. A.; Feitosa, A. P.; Padilha, R.; Alves, L. C.; Porto, I. J.; Batista, R. F.; de Oliveira, J. E.; de Medeiros, E. S., Bonan, P. R.; Castellano, L. R. Evaluation of hemagglutination activity of chitosan nanoparticles using human erythrocytes. BioMed Research International 2015, http://dx.doi.org/10.1155/2015/247965. 